\author{
자폐스펙트럼장애 환자에서의 인지적 공감 및 \\ 정서적 공감의 신경 상관물 \\ 정승원 ${ }^{1)} \cdot$ 손정우 $^{2)} \cdot$ 이승복 $^{3)} \cdot$ 김혜리 $^{3)} \cdot$ 이상익 ${ }^{2)} \cdot$ 신철진 $^{2)}$ \\ 김시경 ${ }^{2)} \cdot$ 주가원 $^{1)} \cdot$ 최상철 ${ }^{4)} \cdot$ 김양렬 $^{5)} \cdot$ 구영진 $^{6)}$ \\ 충북대학교병원 정신건강의학과, ${ }^{1)}$ 충북대학교 의과대학 정신건강의학교실, ${ }^{2}$ 충북대학교 심리학과, ${ }^{3}$ \\ 디딤정신건강의학과의원, ${ }^{4)}$ 서울탑정신건강의학과의원, ${ }^{5)}$ 마인드닥터 주니어 정신건강의학과의원 ${ }^{6}$

\section{Neural Correlates of Cognitive and Emotional Empathy in Patients with Autism Spectrum Disorder} \\ Seungwon Chung, M.D. ${ }^{1)}$, Jung-Woo Son, M.D., Ph.D. ${ }^{2)}$, Seungbok Lee, Ph.D. ${ }^{3)}$, \\ Hei-Rhee Ghim, Ph.D. ${ }^{3)}$, Sang-Ick Lee, M.D., Ph.D. ${ }^{2)}$, Chul-Jin Shin, M.D. ${ }^{2}$, \\ Siekyeong Kim, M.D., Ph.D. ${ }^{2)}$, Gawon Ju, M.D. ${ }^{1}$, Sang Cheol Choi, M.D. ${ }^{4}$, \\ Yang Yeol Kim, M.D. ${ }^{5)}$, and Young Jin Koo, M.D., Ph.D. ${ }^{6}$ \\ ${ }^{1)}$ Department of Psychiatry, Chungbuk National University Hospital, Cheongju, Korea \\ ${ }^{2)}$ Department of Neuropsychiatry, College of Medicine, Chungbuk National University, Cheongju, Korea \\ ${ }^{3)}$ Department of Psychology, Chungbuk National University, Cheongju, Korea \\ ${ }^{4)}$ Didim Psychiatric Clinic, Seoul, Korea \\ ${ }^{5)}$ SeoulTop Child Adolescent Psychiatric Clinic, Seoul, Korea \\ ${ }^{6)}$ MindDoctor's Clinic for Junior, Seoul, Korea
}

Objectives: Individuals with autism spectrum disorder (ASD) are considered to have problems with empathy. It has recently been suggested that there are two systems for empathy; cognitive and emotional. We aimed to investigate the neural response to cognitive and emotional empathy and elucidate the neurobiological aspects of empathy in patients with ASD.

Methods: We recruited patients with ASD ( $\mathrm{N}=17, \mathrm{ASD}$ group) and healthy controls (HC) $(\mathrm{N}=22$, HC group) for an functional magnetic resonance imaging study. All of the subjects were scanned while performing cognitive and emotional empathy tasks. The differences in brain activation between the groups were assessed by contrasting their neural activity during the tasks.

Results: During both tasks, the ASD group showed greater neural activities in the bilateral occipital area compared to the HC group. The ASD group showed more activation in the bilateral precunei only during the emotional empathy task. No brain regions were more activated in the HC group than in the ASD group during the cognitive empathy task. While performing the emotional empathy task, the HC group exhibited greater neural activities in the left middle frontal gyrus and right anterior cingulate gyrus than the ASD group.

Conclusion: This study showed that the brain regions associated with cognitive and emotional empathy in ASD patients differed from those in healthy individuals. The results of this study suggest that individuals with ASD might have defects both in cognitive empathy and in emotional empathy.

KEY WORDS: Autism Spectrum Disorder · Functional Magnetic Resonance Imaging · Cognitive Empathy · Emotional Empathy.

Date received: July 29, 2016 / Date of revision: September 2, 2016 / Date accepted: September 2, 2016

Address for correspondence: Jung-Woo Son, M.D., Ph.D., Department of Psychiatry, Chungbuk National University Hospital, 776 1sunhwan-ro, Seowongu, Cheongju 28644, Korea

Tel: +82.43-269-6187, Fax: +82.43-267-7951, E-mail: mammosss@hanmail.net

이 논문은 2013년 정부(교육부)의 재원으로 한국연구재단의 지원을 받아 수행된 연구임(NRF-2013S1A5B6054557). 이 논문 내용의 일부는 2016년 5월 대한소아청소년정신의학회 춘계학술대회에서 포스터 발표되었음. 


\section{서 론}

자폐스펙트럼장애(autism spectrum disorder, ASD)는 사 회적 상호작용의 결함과 제한적, 반복적인 행동이나 흥미를 특징으로 한다. 이들이 보이는 사회적인 의사소통의 결여가 공 감 능력의 이상과 밀접한 관련이 있다는 데에는 이견이 없다.1)

최근에는 공감이 두 체계로 이루어져 있다는 견해가 지지 를 받고 있다. 즉, 공감이 인지 체계와 정서 체계로 이루어져 있다는 것이다. ${ }^{2)}$ 인지적 공감(cognitive empathy)은 타인의 마음이나 의도를 이해하고 예측하는 능력으로 마음이론이나 정신화 기제와 밀접하게 관련된다. ${ }^{3)}$ 정서적 공감(emotional empathy)은 타인의 감정을 있는 그대로 느끼는 것을 의미한 다. 정서적 공감에는 정서 전염이나 공유되는 고통(shared pain)의 과정이 밀접하게 관련된다. ${ }^{2}$

근래에 인지적 공감, 정서적 공감의 신경 상관물에 대한 연 구들이 이루어지고 있다. Decety 등근 타인의 고통을 관찰 할 때 전대상회(anterior cingulate gyrus)와 뇌섬엽(insula)이 활성화됨을 보였다. Jabbi 등ํ은 얼굴 표정을 관찰할 때 제시 된 감정의 종류에 상관없이 하전두회(inferior frontal gyrus) 가 활성화된다는 것을 확인하였다. 하전두회는 하두정소엽 (inferior parietal lobule)과 더불어 인간의 거울 뉴런계의 핵 심 부위로 행동의 모사나 정서 전염에 관여하며 정서적 공감 과 밀접한 관련이 있다. ${ }^{2)}$ 한편, 타인의 목적이나 믿음 등을 추론할 수 있는 단서가 주어졌을 때, 정신화 체계를 구성하는 측두-두정 접합(temporo-parietal junction), 내측전전두피 질(medial prefrontal cortex), 전설소엽(precuneus)이 활성화 되었으며 이 부위들은 인지적 공감과 관련이 깊다. ${ }^{6)}$ ShamayTsoory 등근 한전두회에 병변이 있는 환자는 정서적 공감 능 력 저하를 보이는 반면, 복내측전전두피질(ventromedial prefrontal cortex)에 병변이 있는 환자는 인지적 공감 능력의 저하를 보인다는 것을 확인했다. 이러한 연구 결과들은 두 가지의 공감을 담당하는 뇌 부위가 서로 다르다는 것을 시사 한다.

$\mathrm{ASD}$ 환자의 인지적 공감 및 정서적 공감 능력을 조사한 선 행 연구들을 살펴보면, Rogers 등이이 아스퍼거 증후군 환자 와 일반인에게 자기 보고식 설문을 시행하여 서로 비교한 결 과 환자군은 인지적 공감 관련 점수는 상대적으로 낮은 반 면 정서적 공감을 반영하는 개인적 고통(personal distress) 과 관련된 점수는 상대적으로 높았다. Dziobek 등희 의 연구에 서는 다면적 공감검사를 시행했을 때, 아스퍼거 증후군 환자 는 일반인에 비해 인지적 공감 능력은 손상을 보이는 반면 정 서적 공감 능력은 차이가 없었다. 최근 $\mathrm{ASD}$ 청소년과 일반
인의 공감 능력을 비교한 연구에서는 $\mathrm{ASD}$ 청소년이 일반인 에 비해 낮은 인지적 공감 능력을 보였고 정서적 공감 능력의 저하는 부정적인 감정에 한해서만 관찰되었다. ${ }^{10)}$ 이처럼 $\mathrm{ASD}$ 에서의 인지적 공감 능력의 저하는 비교적 일관되게 보 고되는 반면 정서적 공감에 대한 결과는 상이하다.

지금까지 ASD 환자를 대상으로 공감 관련 연구가 다수 진 행되었으나 인지적 공감과 정서적 공감 각각의 상황에서 관련 뇌 활성화 부위를 일반인과 비교하여 조사한 연구는 저자들 이 아는 한에서는 없었다. 따라서 본 연구에서는 $\mathrm{ASD}$ 환자의 인지적 공감과 정서적 공감 능력이 대조군과 차이를 보이는 지, 그리고 각각의 공감 상황에서 뇌 활성화의 차이가 나타 나는지 조사하고자 하였다. 이 연구의 가설은 다음과 같다. 1) $\mathrm{ASD}$ 군이 대조군과 인지적 공감 및 정서적 공감 능력에서 차 이를 보일 것이다. 2) 그러한 차이가 뇌 활성화에서도 유의한 차이로 나타날 것이다. 3) 뇌 활성화의 정도가 $\mathrm{ASD}$ 환자의 자폐적 성향이나 공감 능력과도 관계가 있을 것이다.

\section{방 법}

\section{1. 대 상}

$\mathrm{ASD}$ 군은 청주와 서울 지역의 소아청소년 정신건강의학과 에서 모집하였고 대조군은 서울 지역의 정신건강의학과, 고등 학교, 학원에서 지면광고를 통해 모집하였다. 피험자 선별조 건은 다음과 같다. 1) 만 15-22세, 2) 단축형 지능검사 실시 결과 지능지수 70 이상, 3 ) 뇌 자기공명영상(magnetic resonance imaging, MRI) 촬영이 불가능한 요인이 없음, 4) 신체질 환이 없음. ASD군은 Diagnostic and Statistical Manual of Mental Disorders-5(DSM-5)에 의거하여 소아청소년 정신 건강의학과 전문의에 의해 $\mathrm{ASD}$ 를 진단받았으며, 소아청소 년 정신과 질환의 진단을 위한 반 구조화된 면담도구 KiddieSchedule for Affective Disorders and SchizophreniaPresent and Lifetime version(K-SADS-PL) ${ }^{11)}$ 의 한국어판 인 K-SADS-PL-Korean version(K-SADS-PL-K) ${ }^{12)}$ 시행 결과 기타 주요 정신장애의 진단기준을 만족하지 않는 경우 에 한하였다. 대조군은 정신과적인 과거력이 없고, $\mathrm{ASD}$ 의 DSM-5 진단기준을 만족하지 않으며, K-SADS-PL-K에서 어떤 진단기준도 만족하지 않는 경우로 한하였다. 단축형 지 능검사, K-SADS-PL-K 및 평가를 위한 설문지 작성을 모두 완료하였으며, MRI 촬영 시 머리 흔들림으로 인해 탈락하지 않은 피험자들만을 분석 대상으로 하였고 각 군의 나이와 지 능지수를 매칭하였으며, 최종적으로 17 명의 $\mathrm{ASD}$ 군, 22 명의 대조군을 분석하였다. 본 연구는 충북대학교병원 생명윤리 위원회의 승인을 얻었고 만 19세 이상인 피험자는 본인에게, 
만 19세 미만인 피험자는 본인과 부모에게 연구의 목적, 방법 에 대해 충분히 설명한 후 연구에 대한 동의서를 작성하게 하였다.

\section{2. 평가 방법 및 도구}

\section{1) 지능검사}

만 15세인 청소년 피험자의 지능 평가를 위하여 웩슬러 아 동용 지능검사 단축형(The short-form of Wechsler Intelligence Scale for Children-Revised)을 우리 실정에 맞게 보 완한 Korean Educational Developmental Institute-Wechsler Intelligence Scale for Children을 사용하였고 '공통점 찾기', ‘빠진 곳 찾기', '산수, '토막짜기'의 네 가지 소검사를 시 행하였다. 만 16세 이상의 피험자는 한국판 웩슬러 성인용 지능검사 III 단축형(Korean-Wechsler Intelligence Scale III short-form)을 사용하여 지능을 평가하였고 '기본 지식', ‘빠진 곳 찾기'의 두 가지 소검사를 사용하였다.

\section{2) 전체 피험자에게 시행한 설문지}

(1) 자폐스펙트럼지수(Autism Spectrum Quotient, AQ)

Autism Spectrum Quotient(AQ)는 정상 지능을 가진 개인 의 자폐적 성향을 평가하는 자기 보고식 설문지로 점수가 높 을수록 자폐적 성향이 강한 것으로 평가된다. ${ }^{13)}$ 본 연구에서 는 심리학을 전공하고 경력이 20년 이상인 5명의 심리학자들 이 번안한 것을 사용하였다. ${ }^{14)}$ 총 50 개의 검사문항으로 이루 어져 있고 각 문항마다 0점 혹은 1점으로 평가할 수 있어서 총 점은 0-54점으로 분포한다. 검사문항의 신뢰도 계수(Cronbach's $\alpha$ )는 0.71 이었다.

\section{(2) 공감지수(Empathy Quotient, EQ)}

Empathy Quotient(EQ)는 마음을 이해하고 배려하며 공 감하는 능력인 공감하기를 측정하는 자기 보고식 설문지로 점수가 높을수록 공감 정도가 높은 것으로 평가된다. ${ }^{15)}$ 본 연구에서는 심리학을 전공하고 경력이 20년 이상인 5명의 심 리학자들이 번안한 것을 사용하였다. ${ }^{14)}$ 공감과 관련 없는 20 문항과 40개의 검사문항으로 구성되어 있고 각 검사문항은 0-2점으로 평가할 수 있어서 총점은 0-80점으로 분포한다. 검 사문항의 신뢰도 계수(Cronbach's $\alpha$ )는 0.79였다.

(3) 체계화지수-개정판(Systemizing Quotient-Revised, $\mathrm{SQ}-\mathrm{R})$

체계화(systemizing)는 원리에 따라 작동하는 체계를 이
해하여 분석하여 그 규칙을 찾아내는 능력으로 $\mathrm{ASD}$ 환자는 공감 능력은 떨어지는 반면 체계화 능력은 상대적으로 우수 하다고 여겨진다. ${ }^{16)}$ Systemizing Quotient-Revised(SQ-R)는 체계화 능력을 평가할 수 있는 자기 보고식 설문지로 점수가 높을수록 체계화 정도가 높은 것으로 평가된다. ${ }^{17)} 75$ 개의 검 사문항은 각각 0-2점으로 평가할 수 있어서 총점은 0-150점 으로 분포한다.

(4) 대인관계 반응지수(Interpersonal Reactivity Index, IRI)

Interpersonal Reactivity Index(IRI)는 공감 능력을 다차 원적으로 평가하기 위한 설문지이다. ${ }^{18)}$ 4개의 부척도(subscale)로 구성되며 각각은 7문항으로 구성되어 있다. 조망수용 (perspective taking, IRI-PT)은 타인의 관점에서 이해하는 능력을, 공상(fantasy, IRI-FS)은 영화나 소설 등의 등장인 물에 몰입되는 정도를 측정한다. 공감적 관심(empathic concern, IRI-EC)은 타인에 대한 걱정의 정도를, 개인적 고통 (personal distress, IRI-PD)은 고통을 관찰할 때 느끼는 불 편함을 측정한다. 각 문항은 0-4점의 리커트 척도로 되어 있 어 0-112점의 분포를 가진다. 본 연구에서는 Kang 등 ${ }^{19)}$ 이 번 역한 한국판을 사용하였다.

\section{3) ASD군에서만 시행한 설문지}

(1) 한국판 아스퍼거 증후군 진단 척도(Korean version of Asperger Syndrome Diagnostic Scale, K-ASDS)

Asperger Syndrome Diagnostic Scale(ASDS)은 미국에서 아스퍼거 장애를 진단하는 데 광범위하게 사용되는 도구로 대상자를 잘 아는 제 3 자가 작성하도록 되어 있다. ${ }^{20)}$ 본 연구 에서는 한국판인 Korean version of $\mathrm{ASDS}(\mathrm{K}-\mathrm{ASDS})^{21}$ 를 환 자의 부모에게 시행하였다. 총 50 문항으로 각 문항에 대해 '예'는 1점, '아니오'는 0점을 부여하여 총점은 0-50점 사이에 분포한다. 이렇게 산출된 원점수는 표준화 점수로 변환하였다.

(2) 사회적 반응성 척도(Social Responsiveness Scale, SRS)

Social Responsiveness Scale(SRS)은 ASD를 선별하기 위 한 검사로 4점 리커트 척도로 되어 있으며 대상자의 선생님이 나 부모가 평가하도록 되어 있다. ${ }^{22)}$ 질문은 사회적 통찰(social awareness, A), 사회적 인지(social cognition, $\operatorname{Cog}$ ), 사회적 의사소통(social communication, Com), 사회적 동기(social motivation, Mo), 자폐적 기행증(autistic mannerism, Man) 의 다섯 개의 영역으로 나뉘어져 있다. 각 영역의 $\mathrm{T}$ 점수는 
차례대로 SRS-A, SRS-Cog, SRS-Com, SRS-Mo, SRSMan으로 표기하였고, 총점의 T 점수는 SRS-total로 표기하 였다. 본 연구에서는 환자의 부모에게 SRS를 시행하였다.

\section{3. 기능적 뇌 자기공명영상(Functional magnetic resonance imaging, fMRI) 시행 및 데이터 분석}

\section{1) 실험 자극 및 과제}

본 연구는 블록 패러다임의 functional MRI(fMRI) 연구 로 실험자극은 Dziobek 등 ${ }^{23}$ 과 $\mathrm{Kim}^{24}$ 의 연구에서 이용한 자극을 참조하여 제작하였다. International Affective Picture System과 인터넷 검색을 통하여 어떤 배경 상황에 놓여 있는 한 명의 인물이 등장하는 사진들 중에서 절망, 무서움, 슬픔 등 부정적인 감정상태를 나타내는 24장의 사진을 실험 자극으로 택하여 공감 과제를 진행하였다. 인지적 공감 과제 와 정서적 공감 과제에는 서로 동일한 사진을 사용하였고 각 각 4 블록씩 총 8 블록으로 구성하였다. 각 블록은 4초간의 정 보 문장을 시작으로 실행(trial)당 4초로, 총 6회의 실행이 제 시되었고 이후에는 16 초의 휴식기가 적용되었다. 의사(dummy) 6 초를 포함하여 총 촬영 시간은 5 분 58 초였고 블록은 무작 위 순서로 제시되었다. 인지적 공감 과제에서는 피험자에게 사진 속 인물의 감정을 옳게 기술한 단어를 고르도록 하였
고, 정서적 공감 과제에서는 사진 속 인물의 감정에 피험자가 이입되는 정도가 높은지 혹은 낮은지를 고르도록 하였다. 자 극 제시는 E-Prime version 2.0(Psychological Software Tools, Pittsburgh, PA, USA)을 사용하였다. 각 과제 및 휴 식기의 자세한 사항은 다음과 같다.

(1) 인지적 공감 과제(Cognitive empathy task, CE)(Fig. 1) 정보 문장으로 '이 사람이 느끼는 감정은 무엇일까요?'가 나타나고 이어서 사진 자극과 함께 사진 하단의 좌우에는 각 각 감정상태를 기술하는 단어가 하나씩 제시된다. 피험자는 자신이 옳다고 생각하는 단어가 있는 쪽의 손에 쥔 키패드를 누른다. 예를 들어, 사진과 함께 좌측에 '겁에 질린', 우측에 '슬픈'이라는 단어가 제시되고 피험자가 판단하기에 '겁에 질 린'이 사진 속 인물의 감정이라고 생각한다면 좌측 손에 쥔 키패드를 누른다.

(2) 정서적 공감 과제(Emotional empathy task, EE)(Fig. 1) '당신은 이 사람의 감정이 얼마나 느껴지나요?'가 정보 문 장으로 제시되고 사진 자극과 함께 사진 하단의 좌우에 각각 '조금', '많이'가 제시된다. 피험자는 사진에서 표현되는 감정 의 종류와는 상관없이 피험자 자신에게 감정이 전달되어 느 껴지는 정도에 따라 조금 느껴지면 좌측 키패드를, 많이 느

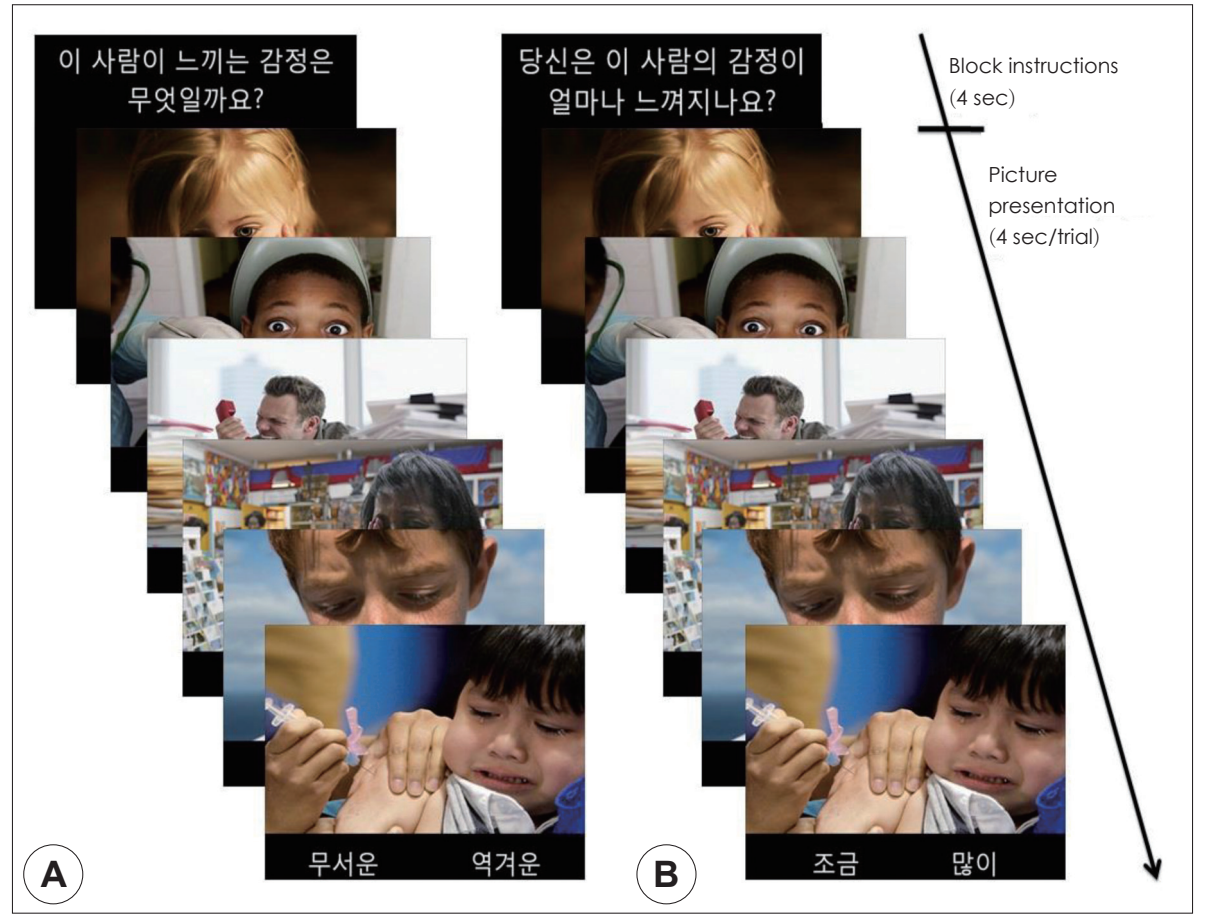

Fig. 1. Examples of each task. A: Cognitive empathy task block was introduced by a question "What is the person feeling?" (4 seconds) and six stimuli were presented (4 seconds per each stimulus). Participants were requested to choose a word that better described the person's feeling. B: Emotional empathy task block was introduced by a question "How much are you feeling for the person?" (4 seconds) and six stimuli were presented (4 seconds per each stimulus). Participants were requested to answer how much they were feeling for the person. Each block was followed by resting condition ( 16 seconds) 
껴지면 우측 키패드를 누른다.

(3) 휴식기(Resting state, R)

휴식기에는 사진 자극이나 과제가 주어지지 않고 화면 중 앙에 +표시만 나오게 된다. 피험자는 fMRI 촬영을 시작하기 전에 휴식기 동안은 아무 생각 없이 +표시만을 응시하도록 교육을 받는다.

시각 자극은 피험자들이 착용한 고글(magnet-compatible three-dimensional goggles)을 통해 제시되었고, 고글 안쪽 에 설치된 eye tracker를 통해 실험자가 피험자의 눈 움직임 을 관찰할 수 있었다. 또한 피험자가 착용한 헤드폰을 통해 실험자가 지시를 할 수 있었고 영상 촬영이 진행되는 동안 움 직이거나 말을 하지 않도록 교육하였다.

\section{2) $\mathrm{FMRI}$ 촬영}

모든 피험자는 고려대학교 뇌영상센터에서 Siemens 3T Tim Trio scanner(Siemens Healthcare, Erlangen, Germany) 로 촬영하였다. fMRI 촬영에는 echo planar imaging sequence에 의한 blood oxygen level dependent 기법을 적용하 였고 각 영상의 slice thickness는 $4.0 \mathrm{~mm}$ 였으며, 그 사이의 간격은 두지 않았다. 그 외 자기공명 변수는 repetition time= $2000 \mathrm{~ms}$, echo time $=30 \mathrm{~ms}$, flip angle $=90^{\circ}$, field of view $=$ $1440 \times 1440 \mathrm{~mm}$, matrix $=64 \times 64 \mathrm{~mm}$ 였다.

\section{3) 데이터 분석}

뇌 영상 자료는 SPM8(Wellcome Trust Centre for Neuroimage, Institute of Neurology, UCL, London, UK)을 이용 하여 분석하였다. 각 피험자의 뇌 영상 자료는 움직임에 대한 보정을 하였고, 해부학적 위치를 파악하기 위해 표준화 작업 을 하였다. 그리고 커널의 크기를 $8 \mathrm{~mm}$ 로 하여 편평화 과정 을 거쳤다. 그 다음, 전체 뇌 분석(whole brain analysis)을 실 시하여 활성화된 뇌 영역을 조사하였다. 한 부피소 수준에서 $\mathrm{p}<.001$ (uncorrected)의 역치를 넘고, 부피소의 범위 수준에 서 50 개의 부피소를 넘는 경우( $\mathrm{k}>50$ voxels)를 활성화 영역 으로 간주하였고, 대조 조건으로는 cognitive empathy taskresting state $(\mathrm{CE}-\mathrm{R})$ (휴식기에 비해 인지적 공감 과제를 수행 할 때 더 활성화된 영역을 조사), emotional empathy taskresting state $(\mathrm{EE}-\mathrm{R})$ (휴식기에 비해 정서적 공감 과제를 수행 할 때 더 활성화된 영역을 조사)의 두 가지를 선정하였다. 먼 저 각 피험자별로 개별 수준 분석(first level analysis)을 실시 한 다음 집단 내 분석(within-group analysis)을 통해 각 집 단 내에서 유의미하게 활성화된 영역을 확인하였고 집단 간 분석(between-group analysis)을 실시하여 두 집단 간 뇌 활
성화 영역의 차이를 비교하였다. 또한 집단 간 분석에서 두 군 간 차이를 보인 뇌 활성화 영역을 관심영역으로 하여 각 피험자들의 그 부위의 활성화 정도를 조사하였다. 이를 수치 화하기 위하여 가장 높이 활성화된 부피소의 반경 $8 \mathrm{~mm}$ 이 내에서의 활성화된 정도를 MarsBaR(http://marsbar.sourceforge.net) toolbox를 이용하여 추출하였다. 이후 각 관심영 역에서 추출된 뇌 활성화 정도와 피험자 특성의 관련성을 알 아보고자 피어슨 상관분석을 시행하였다.

두 군의 연령, 지능지수, 특성은 Shapiro-Wilk test를 통해 정규성을 검증하였고 정규성을 만족하는 경우 독립표본 $\mathrm{t}$-검 정을, 정규성을 만족하지 않는 경우 Mann-Whitney U test 를 이용하여 서로 비교하였다. 성별, 손잡이는 카이제곱 검정 을 이용하여 비교하였다. 통계적인 유의수준은 $\mathrm{p}<.05$ 로 하였 으며 통계처리는 SPSS 21 version(SPSS Inc., Chicago, IL, USA)을 사용하였다.

\section{결 과}

\section{1. 피험자들의 연령, 성별, 지능지수와 특성}

두 군 간 연령, 성별 지능지수, 손잡이 비율은 차이가 없었 다. 또한 15 세와 16 세 이상으로 나누어 지능을 비교했을 때 도 두 군 간 차이는 없었다. $\mathrm{ASD}$ 군의 $\mathrm{AQ}$ 는 대조군보다 높 았고 $(\mathrm{t}=5.638, \mathrm{p}<.001), \mathrm{EQ}$ 는 대조군보다 낮았다 $(\mathrm{t}=-4.116, \mathrm{p}$ $<.001)$. IRI는 두 군 간 차이가 없었으나 $\mathrm{ASD}$ 군의 IRI-PT $(\mathrm{t}=-2.881, \mathrm{p}=.007)$ 와 $\mathrm{IRI}-\mathrm{EC}(\mathrm{t}=-2.233, \mathrm{p}=.032)$ 는 대조군에 비해 낮았다. SQ-R, IRI-FS, IRI-PD는 두 군 간의 차이가 없었다(Table 1).

\section{2. $\mathrm{fMRI}$ 과제 수행에 대한 반응 정확도 및 반응 시간}

인지적 공감 과제에서 $\mathrm{ASD}$ 군의 반응 시간은 평균 1871 $\mathrm{msec}$, 대조군은 평균 $1948 \mathrm{msec}$ 로 서로 차이가 없었고 정답 률도 $\mathrm{ASD}$ 군이 평균 $91.18 \%$, 대조군이 평균 $90.92 \%$ 로 차이 가 없었다. 정서적 공감 과제에서 반응 시간은 $\mathrm{ASD}$ 군이 평균 $1753 \mathrm{msec}$, 대조군이 평균 $1917 \mathrm{msec}$ 였고 두 군 간의 유의한 차이가 없었다. '많이'를 선택한 비율도 $\mathrm{ASD}$ 군, 대조군 각각 평균 $54.16 \%, 60.03 \%$ 로 차이가 없었다.

\section{3. fMRI 촬영 결과}

\section{1) 집단 내 분석 결과}

$\mathrm{ASD}$ 군이 $\mathrm{CE}-\mathrm{R}$ 조건에서 유의한 활성화를 보인 대뇌 부 위는 좌측 설회[lingual gyrus, Brodmann area(BA) 18], 우 측 내전두회(medial frontal gyrus, BA 6,10,11), 좌측 내전 
Table 1. Demographic and other characteristics of ASD group and HC group

\begin{tabular}{|c|c|c|c|c|}
\hline Characteristics & ASD group $(\mathrm{N}=17)$ & HC group $(\mathrm{N}=22)$ & $t$ & $p$ \\
\hline Age (years) $)^{\S}$ & $17.35 \pm 1.80$ & $18.23 \pm 2.11$ & $139.0^{\| \prime}$ & .166 \\
\hline $\mathrm{N}(\%)$ of male ${ }^{\pi}$ & $15(88.24)$ & $21(95.45)$ & $0.704^{* *}$ & .401 \\
\hline$I Q$ & $99.90 \pm 13.40$ & $102.58 \pm 14.26$ & -0.596 & .555 \\
\hline Handedness" & $15 / 2^{\dagger \dagger}$ & $21 / 1^{\dagger \dagger}$ & $0.704^{* *}$ & .401 \\
\hline$A Q$ & $29.59 \pm 7.34$ & $17.46 \pm 6.10$ & 5.638 & $.000^{\ddagger}$ \\
\hline$E Q$ & $25.18 \pm 12.66$ & $43.23 \pm 14.24$ & -4.116 & $.000^{\ddagger}$ \\
\hline$S Q-R$ & $44.00 \pm 21.43$ & $48.14 \pm 21.87$ & -0.591 & .558 \\
\hline$|R|$ & $60.82 \pm 12.81$ & $66.86 \pm 10.52$ & -1.618 & .114 \\
\hline IRI-PT & $15.12 \pm 3.94$ & $18.41 \pm 3.20$ & -2.881 & $.007^{\dagger}$ \\
\hline IRI-FS & $17.06 \pm 5.21$ & $17.32 \pm 5.00$ & -0.158 & .876 \\
\hline IRI-EC & $14.12 \pm 4.72$ & $17.27 \pm 4.10$ & -2.233 & $.032^{*}$ \\
\hline IRI-PD & $14.53 \pm 4.14$ & $13.86 \pm 4.50$ & 0.474 & .638 \\
\hline K-ASDS & $142.04 \pm 18.34$ & - & & \\
\hline SRS & $74.29 \pm 10.90$ & - & & \\
\hline SRS-A & $62.94 \pm 10.47$ & - & & \\
\hline SRS-Cog & $71.06 \pm 11.95$ & - & & \\
\hline SRS-Com & $71.24 \pm 10.47$ & - & & \\
\hline SRS-MO & $72.29 \pm 13.61$ & - & & \\
\hline SRS-Man & $75.00 \pm 12.36$ & - & & \\
\hline
\end{tabular}

Data are presented as mean \pm standard deviation unless otherwise indicated. $*: p<.05, t: p<.01, \pm: p<.001, s$ : comparison by MannWhitney test, " : Mann-Whitney's $U$, ז: comparison by chi-square test, $* *: \chi^{2}$, tt: right-handed/ambidextrous. AQ: autism spectrum quotient, ASD: autism spectrum disorder, EQ: empathy quotient, HC: healthy control, IQ: intelligence quotient, IRI: Interpersonal Reactivity Index, IRI-EC: empathic concern subscale of IRI, IRI-FS: fantasy subscale of IRI, IRI-PD: personal distress subscale of IRI, IRI-PT: perspective taking subscale of IRI, K-ASDS: Korean version of Asperger Syndrome Diagnostic Scale, SQ-R: systemizing quotient-revised, SRS: Social Responsiveness Scale, SRS-A: social awareness subscale of SRS, SRS-Cog: social cognition subscale of SRS, SRS-Com: social communication subscale of SRS, SRS-Mo: social motivation subscale of SRS, SRS-Man: autistic mannerism subscale of SRS

두회(BA 11), 우측 상전두회(superior frontal gyrus, BA 8), 좌측 상전두회(BA 6), 좌측 상측두회(superior temporal gyrus, BA 38)였다. 또한, 좌측 소뇌경사(declive), 우측 소뇌편 도(cerebellar tonsil), 좌측 하반월소엽(inferior semi-lunar lobule)과 같은 소뇌 부위도 유의한 활성화를 보였다. ASD 군이 $\mathrm{EE}-\mathrm{R}$ 조건에서 유의한 활성화를 보인 대뇌 부위는 좌 측 설회(BA 17, 18), 우측 전대상회(BA 32), 우측 상전두회 (BA 8), 좌측 상전두회(BA 6)였다. 소뇌에서도 좌측 소뇌경사, 양측 소뇌편도, 우측 하반월소엽이 유의하게 활성화되었다.

대조군이 $\mathrm{CE}-\mathrm{R}$ 조건에서 유의한 활성화를 보인 대뇌 부위 는 좌측 설회(BA 18), 우측 설회(BA 17), 우측 상전두회(BA 6), 좌측 내전두회(BA 8), 우측 전대상회(BA 32), 좌측 하두 정소엽(BA 7)이었다. 그 외에도 좌측 소뇌정상(culmen), 우 측 소뇌편도가 유의한 활성화를 보였다. 대조군이 $\mathrm{EE}-\mathrm{R}$ 조 건에서 유의한 활성화를 보인 대뇌 부위는 좌측 설회(BA 17 , 18), 우측 상두정소엽(superior parietal lobule, BA 7), 좌측 하두정소엽(BA 40), 우측 중심후회(right postcentral gyrus, BA 1, 2, 40), 좌측 중심후회(left postcentral gyrus, BA 2, 3) 였다. 또한 좌측 소뇌경사도 유의한 활성화를 보였다.
2) 집단 간 분석 결과(Table 2, Fig. 2, 3)

$\mathrm{ASD}$ 군이 대조군에 비해 $\mathrm{CE}-\mathrm{R}$ 조건에서 더 유의하게 활 성화를 보인 영역은 양측 설상엽(cuneus, $\mathrm{BA} 18$ ), 우측 하후 두회(inferior occipital gyrus, BA 19), 우측 설회(BA 18), 우 측 방추상회(fusiform gyrus, BA 19), 좌측 설전부(precuneus, $\mathrm{BA}$ 19)였고, $\mathrm{EE}-\mathrm{R}$ 조건에서 더 유의하게 활성화를 보인 영역은 양측 설상엽(BA 18, 19), 양측 설전부(BA 7), 우측 방 추상회(BA 19)였다.

대조군이 $\mathrm{ASD}$ 군에 비해 $\mathrm{CE}-\mathrm{R}$ 조건에서 더 유의하게 활 성화를 보인 영역은 없었으나, $\mathrm{EE}-\mathrm{R}$ 조건에서 더 유의하게 활성화를 보인 영역은 좌측 중전두회(middle frontal gyrus, $\mathrm{BA} 46)$ 와 우측 전대상회(BA 32)로 나타났다.

\section{4. 상관분석 결과(Table 3, 4)}

$\mathrm{CE}-\mathrm{R}$ 조건에서 $\mathrm{ASD}$ 군이 대조군보다 더 활성화를 보인 영 역을 관심영역으로 하여 $\mathrm{ASD}$ 군 내에서 상관분석을 시행한 결과, 우측 설상엽(BA 18)의 활성화 정도와 $\mathrm{SQ}-\mathrm{R}(\mathrm{r}=0.594$, $\mathrm{p}=.012$ ), 우측 하후두회(BA 19)의 활성화 정도와 SQ-R $(\mathrm{r}=0.708, \mathrm{p}=.001)$ 이 서로 양의 상관관계를 보였다. 우측 방추 상회(BA 19)의 활성화 정도는 IRI-FS와 음의 상관관계를 보 
Table 2. The results of between-group analyses

\begin{tabular}{|c|c|c|c|c|c|c|c|}
\hline \multirow{2}{*}{ Region } & \multirow{2}{*}{ Side } & \multirow{2}{*}{ BA } & \multicolumn{3}{|c|}{ MNI coordinates } & \multirow{2}{*}{$\begin{array}{l}\text { Peak } \\
\text { t-value }\end{array}$} & \multirow{2}{*}{$\begin{array}{c}\text { Cluster size } \\
\text { (voxels) }\end{array}$} \\
\hline & & & $x$ & $y$ & $\mathrm{z}$ & & \\
\hline \multicolumn{8}{|l|}{ ASD group $>\mathrm{HC}$ group } \\
\hline \multicolumn{8}{|l|}{ CE-R } \\
\hline Cuneus & Right & 18 & 20 & -84 & 34 & 4.60 & 789 \\
\hline Cuneus & Right & 18 & 12 & -84 & 30 & 4.55 & \\
\hline Cuneus & Right & 18 & 8 & -92 & 28 & 4.47 & \\
\hline Inferior occipital gyrus & Right & 19 & 42 & -74 & 2 & 4.05 & 137 \\
\hline Lingual gyrus & Right & 18 & 34 & -74 & -6 & 3.95 & \\
\hline Fusiform gyrus & Right & 19 & 30 & -62 & -8 & 3.83 & \\
\hline Cuneus & Left & 18 & -16 & -78 & 30 & 3.99 & 248 \\
\hline Cuneus & Left & 18 & -10 & -82 & 38 & 3.80 & \\
\hline Precuneus & Left & 19 & -6 & -80 & 48 & 3.77 & \\
\hline \multicolumn{8}{|l|}{ EE-R } \\
\hline Cuneus & Right & 18 & 6 & -90 & 30 & 5.09 & 1117 \\
\hline Cuneus & Left & 18 & -12 & -80 & 26 & 4.98 & \\
\hline Cuneus & Left & 19 & -6 & -86 & 40 & 4.29 & \\
\hline Precuneus & Right & 7 & 4 & -60 & 62 & 4.80 & 532 \\
\hline Precuneus & Right & 7 & 10 & -50 & 42 & 3.97 & \\
\hline Precuneus & Left & 7 & 0 & -54 & 44 & 3.90 & \\
\hline Fusiform gyrus & Right & 19 & 30 & -62 & -8 & 4.32 & 78 \\
\hline \multicolumn{8}{|l|}{ HC group>ASD group } \\
\hline \multicolumn{8}{|l|}{$\begin{array}{l}\text { CE-R } \\
\text { (No significant results) }\end{array}$} \\
\hline \multicolumn{8}{|l|}{$\mathrm{EE}-\mathrm{R}$} \\
\hline Middle frontal gyrus & Left & 46 & -54 & 40 & 20 & 4.82 & 139 \\
\hline Anterior cingulate gyrus & Right & 32 & 12 & 24 & 34 & 4.68 & 68 \\
\hline
\end{tabular}

Thresholded at $p<.001$ uncorrected voxel level, extent threshold 50 voxels. ASD: autism spectrum disorder, BA: Brodmann area, CE: cognitive empathy, EE: emotional empathy, HC: healthy control, MNI: Montreal Neuroimaing Institute, R: resting state

였고(r=-0.486, $\mathrm{p}=.048), \mathrm{AQ}$ 와는 양의 상관관계를 보였다 $(\mathrm{r}=$ $0.588, \mathrm{p}=.013)$. 좌측 설상엽(BA 19)의 활성화 정도는 $\mathrm{SQ}-\mathrm{R}$ $(\mathrm{r}=0.516, \mathrm{p}=.034), \mathrm{AQ}(\mathrm{r}=0.520, \mathrm{p}=.003)$ 와 각각 양의 상관관 계를 보였고, 좌측 설전부(BA 19)의 활성화 정도는 SQ-R과 양의 상관관계를 보였다(r=0.731, $\mathrm{p}=.001)$.

한편, $\mathrm{EE}-\mathrm{R}$ 조건에서 $\mathrm{ASD}$ 군이 대조군보다 더 활성화를 보인 영역을 관심영역으로 하여 $\mathrm{ASD}$ 군 내에서 상관분석을 시 행한 결과, 좌측 설상엽(BA 19)의 활성화 정도와 $\mathrm{SQ}-\mathrm{R}(\mathrm{r}=$ $0.588, \mathrm{p}=.013)$, 우측 설전부(BA 7)의 활성화 정도와 SRS$\operatorname{Man}(\mathrm{r}=0.537, \mathrm{p}=.026)$ 이 서로 양의 상관관계를 보였다. 좌측 설전부(BA 7)의 활성화 정도는 $\mathrm{SRS}-\mathrm{Man}(\mathrm{r}=0.581, \mathrm{p}=.014)$, $\mathrm{K}-\mathrm{ASDS}(\mathrm{r}=0.525, \mathrm{p}=.030)$ 와 양의 상관관계를 보였다.

$\mathrm{EE}-\mathrm{R}$ 조건에서 대조군이 $\mathrm{ASD}$ 군보다 더 활성화를 보인 영역을 관심영역으로 하여 대조군 내에서 상관분석을 시행한 결과, 우측 전대상회(BA 32)의 활성화 정도는 $\mathrm{EQ}(\mathrm{r}=0.607$, $\mathrm{p}=.003)$, IRI-PT(r=0.615, $\mathrm{p}=.002)$ 와 양의 상관관계를 보였다.

\section{고 찰}

설문지를 통해 조사한 피험자들의 특성을 비교해 보면, $\mathrm{ASD}$ 군은 대조군에 비해 $\mathrm{AQ}$ 가 높아 자폐적 성향이 두드러 졌고 $\mathrm{EQ}$ 는 낮아 공감 능력이 떨어졌다. IRI는 두 군 간 차이 가 없었으나 IRI-PT와 IRI-EC는 ASD군이 대조군에 비해 낮았다. IRI-PT는 인지적 공감을 가장 잘 반영하고, IRI-EC 는 정서적 공감을 가장 잘 반영한다.9) 본 연구에서 $\mathrm{ASD}$ 군이 낮은 IRI-PT 점수를 보인 것은 선행 연구들과 일치하는 결 과이다. ${ }^{8,9,25)} \mathrm{IRI}-\mathrm{EC}$ 결과로 보면 $\mathrm{ASD}$ 군은 대조군에 비해 정서적 공감 능력도 떨어진다. 그러나 $\mathrm{ASD}$ 환자의 정서적 공 감에 대한 평가 결과는 연구마다 상이하다.3,8,9,10,26) 이는 정서 적 공감 평가 시 인지적 공감과의 경계를 명확히 구분하여 측 정하지 못했거나, 다양한 평가 방법에 따라 다른 결과가 도출 되었을 수 있기 때문일 것이다.

본 연구에서는 휴식기를 기준으로 대조조건을 설정하였기 때문에 특정 기준조건(baseline condition)을 설정하는 실험 


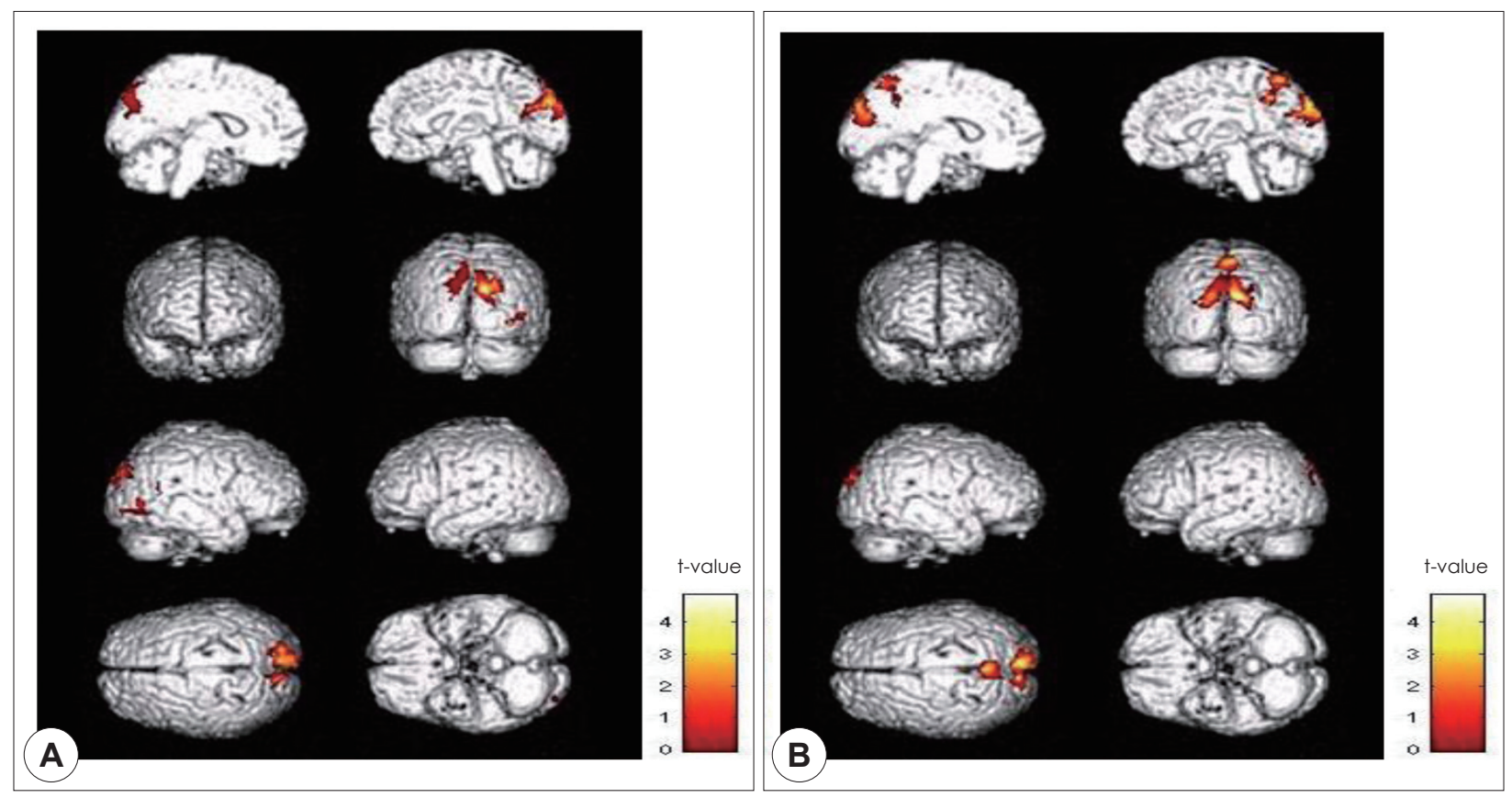

Fig. 2. Brain regions where ASD group showed more activation than HC group. A: In CE vs. resting contrast, ASD group showed relative hyperactivation in the bilateral cunei (BA 18), right inferior occipital gyrus (BA 19), right lingual gyrus (BA 18), right fusiform gyrus (BA 19), and left precuneus (BA 19) compared to HC group. B: In EE vs. resting contrast, ASD group exhibited more activation in the bilateral cunei (BA 18, 19), bilateral precunei (BA 7) and right fusiform gyrus (BA 19) than HC group. ASD: autism spectrum disorder, BA: Brodmann area, CE: cognitive empathy, EE: emotional empathy, HC: healthy control

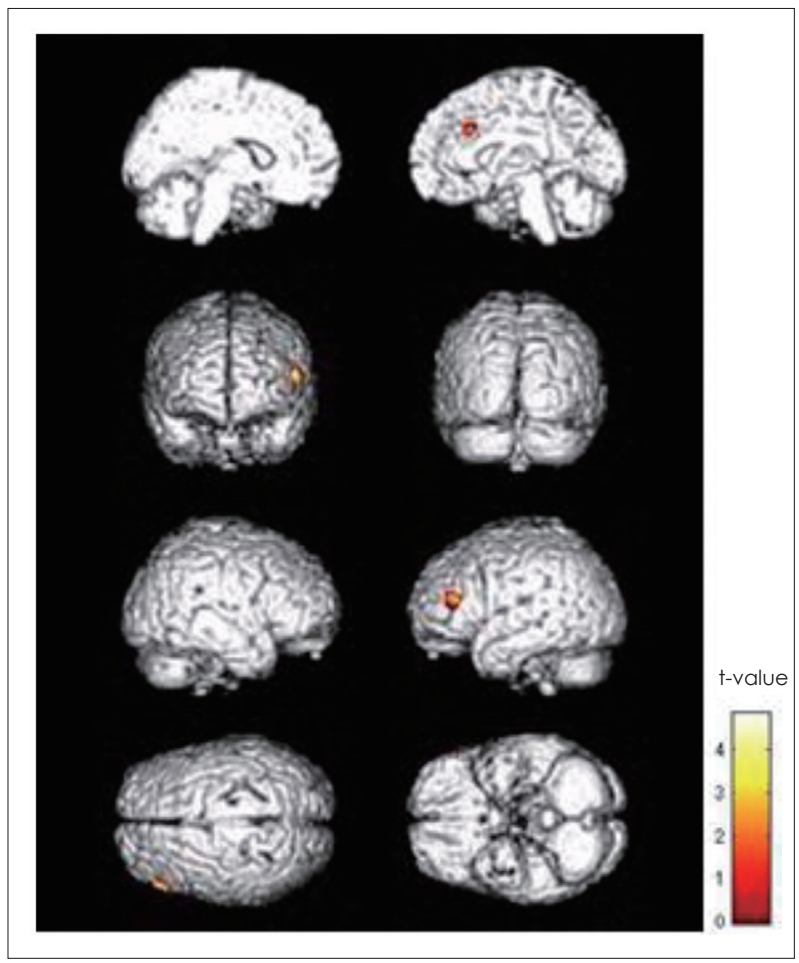

Fig. 3. Brain regions where HC group showed more activation than ASD group in EE vs. resting contrast. HC participants exhibited more activation in the left middle frontal gyrus (BA 46) and right anterior cingulate gyrus (BA 32). ASD: autism spectrum disorder, BA: Brodmann area, EE: emotional empathy, HC: healthy control
방법에 비해 비 특이적인 뇌 활성화가 많이 나타날 수 있다. 그러나 본 연구처럼 특정 기준조건 없이 뇌 활성화를 분석한 다른 연구도 있다. ${ }^{27)}$ 또한 본 연구의 집단 내 분석 결과, $\mathrm{ASD}$ 군과 대조군 각각에서 $\mathrm{CE}-\mathrm{R}$ 조건에서는 인지적 공감과 관 련되는 내전두회의 활성화가, $\mathrm{EE}-\mathrm{R}$ 조건에서는 정서적 공감 과 관련되는 전대상회, 하두정소엽의 활성화가 나타났다는 것은 본 연구의 과제가 관련 뇌 부위를 적절히 활성화시켰다 는 것을 뒷받침한다. 이번 연구는 집단 내 분석 결과보다는 집단 간 분석의 결과에 초점을 맞추어 진행하였다.

집단 간 분석 결과, $\mathrm{ASD}$ 군은 대조군에 비해 두 공감 과제 모두에서 양측 후두부, 특히 BA 18,19 부위가 활성화되었 다. 후두부의 과활성화는 사회불안장애 환자가 사회적인 단 서를 제공받을 때 나타난다는 연구 결과들이 있다. 사회불안 장애 환자가 위협적인 얼굴을 관찰할 때, ${ }^{28)}$ 혹은 얼굴의 감정 과 상관없이 ${ }^{29)} \mathrm{BA} \mathrm{18,19}$ 영역이 과활성화되었다. 약 29\%의 $\mathrm{ASD}$ 환자가 사회불안을 보인다는 사실은 ${ }^{30)} \mathrm{ASD}$ 환자의 사 회불안이 공감 능력 손상의 기전과 밀접하게 관련 있으며 이 로 인해 후두부의 과활성화가 나타났을 가능성을 시사한다.

하후두회는 후두안면영역(occipital face area)으로도 불리 며, 얼굴 인식의 첫 단계에 관여하여 눈, 코 등 각 부위를 구 별하는 역할을 한다. ${ }^{31)}$ 본 연구에서 $\mathrm{ASD}$ 군은 대조군에 비해 인지적 공감 과제에서만 이 부위가 과활성화되었다. 이는 타 
Table 3. Correlation analyses between brain areas showing activity and scales in ASD group participants

\begin{tabular}{|c|c|c|c|c|c|c|c|c|}
\hline & \multirow{2}{*}{ Side } & \multirow{2}{*}{ BA } & \multicolumn{3}{|c|}{ MNI coordinates } & \multirow{2}{*}{ Scale } & \multirow{2}{*}{$r^{\ddagger}$} & \multirow{2}{*}{$p$} \\
\hline & & & $x$ & y & $\mathrm{z}$ & & & \\
\hline \multicolumn{9}{|c|}{ Areas showing activity in response to CE-R } \\
\hline Cuneus & Right & 18 & 12 & -84 & 30 & $S Q-R$ & 0.594 & $.012^{*}$ \\
\hline Inferior occipital gyrus & Right & 19 & 42 & -74 & 2 & $S Q-R$ & 0.708 & $.001^{\dagger}$ \\
\hline \multirow[t]{2}{*}{ Fusiform gyrus } & Right & 19 & 30 & -62 & -8 & IRI-FS & -0.486 & $.048^{*}$ \\
\hline & & & & & & $A Q$ & 0.588 & $.013^{*}$ \\
\hline \multirow[t]{2}{*}{ Cuneus } & Left & 18 & -10 & -82 & 38 & $S Q-R$ & 0.516 & $.034^{*}$ \\
\hline & & & & & & $A Q$ & 0.520 & $.033^{*}$ \\
\hline Precuneus & Left & 19 & -6 & -80 & 48 & $S Q-R$ & 0.731 & $.001^{\dagger}$ \\
\hline \multicolumn{9}{|c|}{ Areas showing activity in response to EE-R } \\
\hline Cuneus & Left & 19 & -6 & -86 & 40 & $S Q-R$ & 0.588 & $.013^{*}$ \\
\hline Precuneus & Right & 7 & 10 & -50 & 42 & SRS-Man & 0.537 & $.026^{*}$ \\
\hline \multirow[t]{2}{*}{ Precuneus } & Left & 7 & 0 & -54 & 44 & SRS-Man & 0.581 & $.014^{*}$ \\
\hline & & & & & & K-ASDS & 0.525 & $.030 *$ \\
\hline
\end{tabular}

*: $\mathrm{p}<.05,+: \mathrm{p}<.01$, *: Pearson's correlation coefficient. AQ: autism spectrum quotient, ASD: autism spectrum disorder, BA: Brodma$\mathrm{nn}$ area, CE: cognitive empathy task, EE: emotional empathy task, IRI-FS: fantasy subscale of Interpersonal Reactivity Index, K-ASDS: Korean version of Asperger Syndrome Diagnostic Scale, MNI: Montreal Neuroimaing Institute, R: resting state, SQ-R: systemizing quotient-revised, SRS-Man: autistic mannerism subscale of Social Responsiveness Scale

Table 4. Correlation analyses between brain areas showing activity and scales in HC group participants

\begin{tabular}{|c|c|c|c|c|c|c|c|c|}
\hline & \multirow{2}{*}{ Side } & \multirow{2}{*}{ BA } & \multicolumn{3}{|c|}{ MNI coordinates } & \multirow{2}{*}{ Scale } & \multirow{2}{*}{$r^{\dagger}$} & \multirow{2}{*}{$\mathrm{p}$} \\
\hline & & & $x$ & $\mathrm{y}$ & $\mathrm{z}$ & & & \\
\hline \multicolumn{9}{|c|}{ Areas showing activity in response to EE-R } \\
\hline \multirow[t]{2}{*}{ Anterior cingulate gyrus } & Right & 32 & 12 & 24 & 34 & $E Q$ & 0.607 & $.003 *$ \\
\hline & & & & & & IRI-PT & 0.615 & $.002^{*}$ \\
\hline
\end{tabular}

*: $\mathrm{p}<.01,+$ : Pearson's correlation coefficient. BA: Brodmann area, EE: emotional empathy task, EQ: empathy quotient, HC: healthy control, IRI-PT: perspective taking subscale of Interpersonal Reactivity Index, MNI: Montreal Neuroimaing Institute, R: resting state

인의 감정을 인지적으로 알아차리는 것에 대한 어려움으로 기본적인 얼굴 인식 과정에 관여하는 후두안면영역까지 보상 적으로 활성화된 것으로 해석할 수 있다. 즉, $\mathrm{ASD}$ 군은 단순 히 타인의 감정을 그대로 느끼는 과정보다 그와 관련한 인지 적인 과정에 더욱 어려움을 느낄 것이라 추측할 수 있다.

$\mathrm{ASD}$ 군에서 보인 또 다른 뇌 활성화 패턴은 정서적 공감 과 제 수행 시에 대조군에 비해 양측 전설부가 과활성화되었다 는 것이다. 전설부, 내측 전전두피질, 전대상회로 구성되는 중 앙 피질 구조는 자기참조과정(self-referential processing)에 중요한 신경 상관물이다. ${ }^{32}$ 정서적 공감 상황에서는 타인의 감정을 그대로 느끼는 것뿐 아니라 자기참조과정을 통해 자 신과 타인을 구분할 수 있어야 한다. ${ }^{33)}$ 본 연구에서 정서적 공감 과제 수행 시에 $\mathrm{ASD}$ 군은 대조군에 비해 우측 전대상회 가 상대적으로 저활성화를 보였다. 따라서 정서적 공감 과제 수행 시에 환자군은 자기참조에 관여하는 중앙 피질 구조들 사이의 불균형이 발생할 수 있음을 추측할 수 있다.

정서적 공감 과제 수행 시에 대조군이 $\mathrm{ASD}$ 군에 비해 활 성화를 보인 우측 전대상회는 정서적 공감과 관련이 깊고, 좌 측 중전두회는 정서적 공감에 밀접하게 관계되는 하전두회
와 바로 인접하는 부위이다. 고통에 대한 공감과 가장 특징적 으로 관련되는 뇌 부위는 뇌섬엽, 하전두회, 전대상회이다. ${ }^{34}$ 본 연구에서 제시된 자극들은 모두 부정적 감정을 내포했던 것을 고려하면, $\mathrm{ASD}$ 군이 위의 두 영역의 상대적 저활성화를 보인 것은 $\mathrm{ASD}$ 환자가 적어도 부정적인 감정에 대한 정서적 공감 능력은 손상이 있음을 시사한다. 이는 ASD 환자를 대상 으로 다면적 공감검사를 시행한 최근 연구의 결과와도 부합 한다. ${ }^{10)}$

본 연구에서 상관분석 결과, $\mathrm{ASD}$ 군에서 $\mathrm{BA} 18,19$ 부위의 활성화 정도가 $\mathrm{AQ}$ 와 양의 상관관계를 보였다. 이는 $\mathrm{ASD}$ 군 내에서도 자폐적 성향이 강할수록 인지적 공감에 더욱 어려 움을 느끼고 보상적으로 $\mathrm{BA} 18,19$ 가 더 과활성화되는 것이 라고 해석할 수 있다. $\mathrm{ASD}$ 군에서 $\mathrm{SQ}-\mathrm{R}$ 도 $\mathrm{BA} 18,19$ 부위 의 활성화 정도와 양의 상관관계를 보인 것도 눈여겨볼 만하 다. 극단적 남성 뇌 이론(extreme male brain theory of autism)에 의하면 남성은 여성에 비해 공감보다 체계화가 상대 적으로 더 발달되는데, $\mathrm{ASD}$ 는 이러한 남성적 인지성향의 극 단적인 형태이다. ${ }^{35)} \mathrm{ASD}$ 군에서 $\mathrm{BA} 18,19$ 부위의 활성도가 $\mathrm{SQ}-\mathrm{R}$ 과 양의 상관관계를 보인 것은 극단적 남성 뇌 이론과 
상통하는 결과이다. 한편 대조군에서는 우측 전대상회의 활 성화 정도가 $\mathrm{EQ}$ 와 양의 상관관계를 보였다. 이는 일반인이 더라도 공감 능력이 높을수록 정서적 공감과 관련이 있는 우 측 전대상회가 더 잘 활성화된다는 것을 보여준다. $\mathrm{ASD}$ 의 사회적 상호작용 결핍과 관련된 증상은 일반 인구에까지 확 장시킬 수 있는 정량적인 특성을 갖는다. ${ }^{36)}$

이번 연구의 제한점으로는 첫째, ASD 선별에 DSM-5 진 단 기준을 근거로 하였으나 Autism Diagnostic Observation Schedule $^{37)}$ 이나 Autism Diagnostic Interview-Revised ${ }^{38)}$ 와 같은 구조화된 선별 도구를 적용하지 못했다. 그러나 본 연 구의 환자군은 다년의 임상경험을 가진 소아청소년 정신건강 의학과 전문의들에 의해 진단받았으며 $\mathrm{AQ}$ 를 통해 조사한 자폐적 특성은 대조군에 비해 거의 2배가량 높았다. 둘째, 표 본의 수가 적었다. 이에 대하여 각 군의 나이 및 지능지수를 매칭하여 통계적인 유의성을 확보하려 하였다. 셋째, 과제의 길이가 총 5 분 58 초로 짧았다. 그러나 $\mathrm{ASD}$ 환자에서 집중력 저하의 문제 및 이로 인한 머리 흔들림 문제가 흔하다는 사 실을 고려하여 과제의 총 시간을 정하였다. 넷째, 본 연구의 $\mathrm{ASD}$ 군은 지능지수 70 이상으로 한정되었다. ASD의 50-70\% 에서 지적장애가 동반된다는 사실 ${ }^{39)}$ 을 고려하면 이번 연구 결 과를 모든 $\mathrm{ASD}$ 환자에게 확장하기엔 어려움이 있다. 그러나 과제 수행에는 일정 수준 이상의 지능이 필수적이며, 대부분 의 fMRI 연구에서는 지능지수 70 이상의 피험자를 대상으로 한 연구가 시행되고 있다. 또한 사회적 상호작용 및 공감 능 력의 이상은 모든 $\mathrm{ASD}$ 환자의 핵심 증상이라는 점에서 본 연구 결과의 의미를 찾을 수 있다. 다섯째, 실험 참가자들의 연령대가 만 15 세부터 22세까지로 한정되었기 때문에 더 다 양한 연령대에서 보일 수 있는 뇌 활성화의 차이를 반영하지 못하였다.

\section{결 론}

공감 능력에 대한 설문조사 결과 $\mathrm{ASD}$ 군은 대조군에 비해 인지적, 정서적 공감 능력이 떨어졌다. 뇌 영상 분석 결과 $\mathrm{ASD}$ 군은 정서적 및 인지적 공감 시에 후두부가 과활성화되었고 이는 사회불안이나 얼굴 인식 관련 부위의 보상적 과활성화 등이 복합적으로 작용한 결과로 보인다. 정서적 공감 시에 환 자군은 하전두회의 인접 부위인 중전두회, 전대상회가 상대 적으로 저활성화되었다. 이는 $\mathrm{ASD}$ 환자가 적어도 부정적 정 서에 대한 정서적 공감 능력에 손상이 있을 가능성을 시사한 다. 향후 $\mathrm{ASD}$ 환자의 공감 문제에 대한 병태생리를 이해하 고 치료에 적용하기 위해 다양하고 세밀한 방법론을 통해 신 경생물학적인 요소들을 밝혀야 할 것이다.
중심 단어: 자폐스펙트럼장애·기능적 뇌 자기공명영상 인지적 공감·정서적 공감.

\section{Conflicts of Interest}

The authors have no financial conflicts of interest.

\section{References}

1) Decety J, Jackson PL. The functional architecture of human empathy. Behav Cogn Neurosci Rev 2004;3:71-100.

2) Shamay-Tsoory SG. The neural bases for empathy. Neuroscientist 2011;17:18-24.

3) Smith A. The empathy imbalance hypothesis of autism: a theoretical approach to cognitive and emotional empathy in autistic development. Psychol Rec 2009;59:489-510.

4) Decety J, Yang CY, Cheng Y. Physicians down-regulate their pain empathy response: an event-related brain potential study. Neuroimage 2010;50:1676-1682.

5) Jabbi M, Swart M, Keysers C. Empathy for positive and negative emotions in the gustatory cortex. Neuroimage 2007;34:1744-1753.

6) Van Overwalle F, Baetens K. Understanding others' actions and goals by mirror and mentalizing systems: a meta-analysis. Neuroimage 2009;48:564-584.

7) Shamay-Tsoory SG, Aharon-Peretz J, Perry D. Two systems for empathy: a double dissociation between emotional and cognitive empathy in inferior frontal gyrus versus ventromedial prefrontal lesions. Brain 2009;132(Pt 3):617-627.

8) Rogers K, Dziobek I, Hassenstab J, Wolf OT, Convit A. Who cares? Revisiting empathy in Asperger syndrome. J Autism Dev Disord 2007;37:709-715.

9) Dziobek I, Rogers K, Fleck S, Bahnemann M, Heekeren HR, Wolf OT, et al. Dissociation of cognitive and emotional empathy in adults with Asperger syndrome using the Multifaceted Empathy Test (MET). J Autism Dev Disord 2008;38:464-473.

10) Mazza M, Pino MC, Mariano M, Tempesta D, Ferrara M, De Berardis $\mathrm{D}$, et al. Affective and cognitive empathy in adolescents with autism spectrum disorder. Front Hum Neurosci 2014;8:791.

11) Kaufman J, Birmaher B, Brent D, Rao U, Flynn C, Moreci P, et al. Schedule for Affective Disorders and Schizophrenia for SchoolAge Children-Present and Lifetime version (K-SADS-PL): initial reliability and validity data. J Am Acad Child Adolesc Psychiatry 1997;36:980-988.

12) Kim YS, Cheon KA, Kim BN, Chang SA, Yoo HJ, Kim JW, et al. The reliability and validity of Kiddie-Schedule for Affective Disorders and Schizophrenia-Present and Lifetime version- Korean version (K-SADS-PL-K). Yonsei Med J 2004;45:81-89.

13) Baron-Cohen $S$, Wheelwright $S$, Skinner R, Martin J, Clubley E. The autism-spectrum quotient (AQ): evidence from Asperger syndrome/high-functioning autism, males and females, scientists and mathematicians. J Autism Dev Disord 2001;31:5-17.

14) Park EH, Ghim HR, Cho KJ, Koo JS. Individual differences in empathizing and systemizing. Korean J Woman Psychol 2009;14: 269-286.

15) Baron-Cohen S, Wheelwright $S$. The empathy quotient: an investigation of adults with Asperger syndrome or high functioning autism, and normal sex differences. J Autism Dev Disord 2004;34: $163-175$.

16) Baron-Cohen S. Autism: the empathizing-systemizing (E-S) theory. Ann N Y Acad Sci 2009;1156:68-80.

17) Wheelwright S, Baron-Cohen S, Goldenfeld N, Delaney J, Fine D, Smith R, et al. Predicting Autism Spectrum Quotient (AQ) from the Systemizing Quotient-Revised (SQ-R) and Empathy Quotient (EQ). Brain Res 2006;1079:47-56.

18) Davis MH. A multi-dimensional approach to individual differenc- 
es in empathy. JCAS Cat Sel Doc Psychol 1980;75:989-1015.

19) Kang I, Kee S, Kim SE, Jeong B, Hwang JH, Song JE, et al. Reliability and validity of the Korean-version of Interpersonal Reactivity Index. J Korean Neuropsychiatr Assoc 2009;48:352-358.

20) Myles BS, Bock SJ, Simpson RL. Asperger Syndrome Diagnostic Scale. Austin: Pro-ED;2001.

21) Kim JH, Shin MS. A study of reliability \& validity for the Korean version of Asperger syndrome diagnostic scale. J Korean Acad Child Adolesc Psychiatry 2005;16:98-105.

22) Constantino JN, Gruber CP. Social Responsiveness Scale (SRS). Los Angeles: Western Psychological Services;2005.

23) Dziobek I, Preissler S, Grozdanovic Z, Heuser I, Heekeren HR, Roepke S. Neuronal correlates of altered empathy and social cognition in borderline personality disorder. Neuroimage 2011;57:539-548.

24) Kim JE. Cognitive and emotional empathy in adolescent ADHD: an fMRI study [dissertation]. Cheongju: Chungbuk National Univ.; 2015.

25) Golan O, Baron-Cohen S, Hill JJ, Rutherford MD. The 'Reading the Mind in the Voice' test-revised: a study of complex emotion recognition in adults with and without autism spectrum conditions. $\mathrm{J}$ Autism Dev Disord 2007;37:1096-1106.

26) Lockwood PL, Bird G, Bridge M, Viding E. Dissecting empathy: high levels of psychopathic and autistic traits are characterized by difficulties in different social information processing domains. Front Hum Neurosci 2013;7:760

27) Passarotti AM, Sweeney JA, Pavuluri MN. Neural correlates of incidental and directed facial emotion processing in adolescents and adults. Soc Cogn Affect Neurosci 2009;4:387-398.

28) Straube T, Kolassa IT, Glauer M, Mentzel HJ, Miltner WH. Effect of task conditions on brain responses to threatening faces in social phobics: an event-related functional magnetic resonance imaging study. Biol Psychiatry 2004;56:921-930.
29) Straube T, Mentzel HJ, Miltner WH. Common and distinct brain activation to threat and safety signals in social phobia. Neuropsychobiology 2005;52:163-168.

30) Simonoff E, Pickles A, Charman T, Chandler S, Loucas T, Baird G. Psychiatric disorders in children with autism spectrum disorders: prevalence, comorbidity, and associated factors in a population-derived sample. J Am Acad Child Adolesc Psychiatry 2008;47:921929.

31) Pitcher D, Walsh V, Duchaine B. The role of the occipital face area in the cortical face perception network. Exp Brain Res 2011;209: 481-493.

32) Uddin LQ, Iacoboni M, Lange C, Keenan JP. The self and social cognition: the role of cortical midline structures and mirror neurons. Trends Cogn Sci 2007;11:153-157.

33) de Vignemont F, Singer T. The empathic brain: how, when and why? Trends Cogn Sci 2006;10:435-441.

34) Lamm C, Decety J, Singer T. Meta-analytic evidence for common and distinct neural networks associated with directly experienced pain and empathy for pain. Neuroimage 2011;54:2492-2502.

35) Baron-Cohen S. The extreme male brain theory of autism. Trends Cogn Sci 2002;6:248-254.

36) Constantino JN, Todd RD. Autistic traits in the general population: a twin study. Arch Gen Psychiatry 2003;60:524-530.

37) Lord C, Rutter M, Goode S, Heemsbergen J, Jordan H, Mawhood L, et al. Autism diagnostic observation schedule: a standardized observation of communicative and social behavior. J Autism Dev Disord 1989;19:185-212.

38) Le Couteur A, Lord C, Rutter M. The Autism Diagnostic InterviewRevised (ADI-R). Los Angeles: Western Psychological Services; 2003.

39) Matson JL, Shoemaker M. Intellectual disability and its relationship to autism spectrum disorders. Res Dev Disabil 2009;30:1107-1114. 